\title{
Historico-linguistic analysis of toponyms of Elabuga county of Vyatsky province (Slavonic layer)
}

\author{
Almira K.Garaeva, , Ildar G.Ahmetzyanov , Narkiz K.Moullagaliev \\ (Volga Region) Federal University, Kazan
}

The article deals with the attempts to trace etymological characteristics of the territorial toponyms related to the late eighteen century. One of the primary and important tasks of modern onomastics is a deep historical linguistic analysis of onomastic material, generalization of the research results and identification of linguistic patterns of formation and development. Research on onomastics provides valuable material for clarifying a range of complex issues of the language history and people themselves. Historically restoring the names of settlements of Elabuga county we strive to highlight the most socially important ethnic situation in the Vyatsky province in the past centuries. After all, toponyms are historical monuments reflecting life, worldview of the people who lived there, their names, their activities and so on. Saved for science, toponyms can tell a lot, if they are timely and carefully recorded and correctly decoded, as each name is a word that evolves according to the language laws. In this regard, the relevance of this study is determined by the fact that the study of toponymic units remains one of the most important tasks of linguistics, since it is necessary to faster fix all that is still preserved and there by save language values for science. In our paper we have analyzed toponyms only of the Slavonic layer of Elabuga country. We have made their lexico-semantic as well as their structural analysis. The materials of this paper can be recommended for historians, scholars and linguists to use in modern practice.

Keywords: material, onomastics, research, semantics, structure 